\title{
High Performance in Screening for Colorectal Cancer: A Practice Partner Research Network (PPRNet) Case Study
}

\author{
Lynne S. Nemeth, PhD, RN, Paul J. Nietert, PhD, and Steven M. Ornstein, MD
}

Introduction: Colorectal cancer (CRC) screening is recommended for average-risk adults age 50 and older, yet half of eligible US adults are not current. This case study of highest performing practices within the Colorectal Screening in Primary Care study (C-TRIP) explains practice strategies used and provides a model for improving CRC screening in primary care.

Methods: A case study design was used to analyze practice performance data and qualitative data obtained from site visits, network meetings, and correspondence. The Practice Partner Research Network (PPRNet) Translating Research into Practice (TRIP) Quality Improvement (QI) model provided an analytic framework to evaluate the 5 highest-performing practices in the C-TRIP intervention. Practice strategies were grouped within the concepts: prioritize performance (PP), redesign delivery system (RDS), electronic medical record tools (EMR), and activate the patient (AP).

Results: Thirteen specific practice strategies were exemplified within these four concepts (PP, RDS, EMR, AP). Most or all of these strategies were used by practices that achieved the highest proportion (up to $\mathbf{7 8 \%}$ ) of adults screened for CRC.

Conclusions: Primary care practices achieving a high proportion of CRC screening use systematic processes in the organization of their care. This case study provides a framework to organize systems that increase early detection and prevention of colorectal cancer. (J Am Board Fam Med 2009;22: 141-146.)

Colorectal cancer (CRC) is the second highest cause of cancer-related deaths in the United States. Screening for early-stage CRC and precursor lesions decreases CRC mortality. Broad consensus guidelines recommend screening all adults at average risk beginning at age 50 and those at increased risk earlier. Although CRC screening has been increasing, approximately one half of those eligible in

This article was externally peer reviewed.

Submitted 22 May 2008; revised 10 July 2008; accepted 22 July 2008 .

From the College of Nursing (LSN); the Department of Bioinformatics, Biometry, and Epidemiology (PJN); and the Department of Family Medicine (SMO), Medical University of South Carolina, Charleston.

Funding: This research is supported by National Institutes of Health, National Cancer Institute, grant 1 R01 CA112389-01A1.

Conflict of interest: All of the authors are supported in part through the National Cancer Institute for this research. Dr. Ornstein is a consultant to McKesson Practice Partner for work unrelated to this manuscript. The other authors declare no potential conflicts of interest related to this manuscript.

Corresponding author: Lynne S. Nemeth, PhD, RN, College of Nursing, Medical University of South Carolina, 99 Jonathan Lucas St MSC 160, Charleston, SC 29425 (E-mail: nemethl@musc.edu). the United States are not current with recommended screening. ${ }^{1}$

As with many preventive services, primary care clinician recommendation and facilitation of completion are important predictors of CRC screening. ${ }^{2}$ Given competing demands in primary care, systematic approaches are needed to support this process. Efforts to redesign systems to improve CRC screening through teamwork, electronic medical records (EMRs), patient-centered care, and other initiatives are underway. ${ }^{3}$

One approach to quality improvement is the identification and dissemination of strategies adopted as "best practices." The Practice Partner Research Network's (PPRNet) Colorectal Cancer Screening in Primary Care (C-TRIP) study is evaluating the impact of this approach. PPRNet is a national primary care, practice-based research network whose members use a common EMR (McKesson Practice Partner, McKesson Corp., Seattle, WA). C-TRIP is a group randomized trial within 32 PPRNet practices that has been approved by the Institutional Review Board at the Medical University of South Carolina. Through interven- 


\begin{tabular}{|c|c|c|c|c|}
\hline $\begin{array}{l}\text { Eligible Adults Up-to-Date } \\
\text { with CRC Screening (\%) }\end{array}$ & State & Providers (n) & MDs (n) & $\begin{array}{c}\text { Patients } \geq 50 \text { Years } \\
\text { of Age (n) }\end{array}$ \\
\hline 78.3 & FL & 1 & 1 & 267 \\
\hline 72.7 & WI & 3 & 2 & 1084 \\
\hline 70.7 & $\mathrm{TN}$ & 2 & 2 & 1625 \\
\hline 64.6 & $\mathrm{CO}$ & 4 & 2 & 2106 \\
\hline 59.7 & $\mathrm{NC}$ & 5 & 3 & 2461 \\
\hline
\end{tabular}

CRC, colorectal cancer; FL, Florida; WI, Wisconsin; TN, Tennessee; CO, Colorado; NC, North Carolina.

tions including practice site visits for academic detailing and process improvement planning, network meetings to share best practice approaches, and practice performance reports, ${ }^{4}$ the study aims to encourage the adoption of effective strategies to increase the recommendations for and receipt of CRC screening. This report describes the identification of these improvement strategies, using a case study methodology from 5 practices with the highest proportions of screening at the baseline of the C-TRIP study. A case study method is ideally suited to answer "how" questions seeking to examine the context within a particular situation. ${ }^{5}$

\section{Methods}

The approach PPRNet uses to extract data from the EMRs of its member practices and produce performance reports have been described elsewhere. ${ }^{6}$ For the C-TRIP study, during the first 6 months of 2007 participating practices reviewed the entirety of the EMRs for patients 50 years of age or older to assure that any information concerning completed colonoscopy, flexible sigmoidoscopy, or at-home fecal occult blood testing within recommended intervals was documented in the health maintenance (HM) section. After the July 2007 extract was performed, 16 practices were randomized into the study intervention group and 16 to the control group. The top 5 practices in the intervention group, based on data recorded in the HM section, were selected as subjects for this case study.

The primary sources of data for this case study were presentations from physicians and nurse liaisons from each of the 5 practices at a November 3 , 2007 meeting attended by representatives of all practices in the intervention group and the research team. The presenters were asked to address specifically the processes used by their practices to achieve high rates of screening. These sessions were recorded using an Olympus DSS-330 digital voice recorder (Olympus America, Inc., Center Valley, PA). Two of the authors (LN, SO) listened to the recordings and noted the key strategies used by these practices. After independent review of the key findings, they discussed and resolved any different interpretations. The PPRNet-TRIP quality improvement (QI) model $^{4}$ was used as a framework for analysis. This model emphasizes prioritizing performance, staff involvement, system redesign, patient activation, and enhanced use of the practice EMR tools. A compendium of practice improvement strategies identified within a previous PPRNet study ${ }^{7}$ served as exemplars of the activities that practices engaged within PPRNet-TRIP might adopt. Observations at practice site visits recorded within field notes from August 2007 through April 2008 provided additional data sources to refine the analyses. Discussions at these site visits probed practice adoption of specific CRC screening strategies rated within a survey completed by the practice liaisons at the baseline. E-mail and telephone correspondence with the liaisons provided an opportunity for member checking to assure the credibility of the findings. ${ }^{8}$

\section{Results}

As of July 1, 2007, CRC screening was up-to-date in $59.7 \%$ to $78.3 \%$ of the eligible, active patients within the top 5 practices. Table 1 displays selected characteristics of the practices. The practice with the highest performance was a concierge practice limited to approximately 300 patients for whom the solo physician is retained through an annual membership fee. Three of the practices were practices with 2 physicians/partners. Four of the practices were family medicine centers, and one practice was an internal medicine practice. All of these practices 
Table 2. Strategies to Achieve High Performance in Colorectal Cancer Screening

\begin{tabular}{|c|c|c|c|c|c|c|}
\hline Improvement Model & Strategies & FL & WI & $\mathrm{TN}$ & $\mathrm{CO}$ & $\mathrm{NC}$ \\
\hline \multirow[t]{3}{*}{ Prioritize performance } & Commit to practice changes needed to improve. & $\mathrm{x}$ & $\mathrm{x}$ & $\mathrm{x}$ & & $\mathrm{x}$ \\
\hline & $\begin{array}{l}\text { Have regular practice meetings to review } \\
\text { improvement approaches and their impact. }\end{array}$ & & $\mathrm{x}$ & $\mathrm{x}$ & $\mathrm{x}$ & $\mathrm{x}$ \\
\hline & $\begin{array}{l}\text { Offer patients choice of recommended CRC } \\
\text { screening options. }\end{array}$ & $\mathrm{x}$ & $\mathrm{x}$ & $\mathrm{x}$ & $\mathrm{x}$ & $\mathrm{x}$ \\
\hline \multirow[t]{4}{*}{ Delivery system design } & $\begin{array}{l}\text { Adopt and publicize recommendation for regular } \\
\text { health maintenance visits. }\end{array}$ & $\mathrm{x}$ & $\mathrm{x}$ & $\mathrm{x}$ & $\mathrm{x}$ & $\mathrm{x}$ \\
\hline & Remind patients of needed health maintenance visits. & $\mathrm{x}$ & $\mathrm{x}$ & $\mathrm{x}$ & $\mathrm{x}$ & $\mathrm{x}$ \\
\hline & Standing orders for CRC screening. & $\mathrm{x}$ & $\mathrm{x}$ & & & $\mathrm{x}$ \\
\hline & Review CRC screening status at all patient visits. & & $\mathrm{x}$ & $\mathrm{x}$ & $\mathrm{x}$ & $\mathrm{x}$ \\
\hline \multirow[t]{3}{*}{ Electronic medical record tools } & $\begin{array}{l}\text { Maintain accurate information in the health } \\
\text { maintenance tables. }\end{array}$ & $\mathrm{x}$ & $\mathrm{x}$ & $\mathrm{x}$ & $\mathrm{x}$ & $\mathrm{x}$ \\
\hline & $\begin{array}{l}\text { Empower all staff to review health maintenance table } \\
\text { at all patient contacts. }\end{array}$ & $\mathrm{x}$ & $\mathrm{x}$ & $\mathrm{x}$ & $\mathrm{x}$ & $\mathrm{x}$ \\
\hline & $\begin{array}{l}\text { Use reports to identify and contact patients not } \\
\text { current with CRC screening. }\end{array}$ & & $\mathrm{x}$ & $\mathrm{x}$ & & \\
\hline \multirow[t]{3}{*}{ Patient activation } & $\begin{array}{l}\text { Repeat messages to patients who do not initially } \\
\text { agree to screening. }\end{array}$ & $\mathrm{x}$ & $\mathrm{x}$ & $\mathrm{x}$ & $\mathrm{x}$ & $\mathrm{x}$ \\
\hline & $\begin{array}{l}\text { Provide patient education materials about CRC } \\
\text { screening. }\end{array}$ & & $\mathrm{x}$ & & $\mathrm{x}$ & $\mathrm{x}$ \\
\hline & $\begin{array}{l}\text { Contact patients that have not completed ordered } \\
\text { screening. }\end{array}$ & $\mathrm{x}$ & $\mathrm{x}$ & $\mathrm{x}$ & $\mathrm{x}$ & $\mathrm{x}$ \\
\hline
\end{tabular}

CRC, colorectal cancer; FL, Florida; WI, Wisconsin; TN, Tennessee; CO, Colorado; NC, North Carolina.

had previous experience with the PPRNet-TRIP QI model through participation in previous demonstration projects or group randomized trials.

Analyses of the qualitative data revealed a common set of strategies used within these practices and related to their high level of CRC screening performance. Not every strategy was adopted by each practice because practice styles varied with the local context; however, these 5 practices shared many common characteristics. Table 2 provides an overview of the strategies, which are discussed below.

\section{Prioritize Performance}

All of these practices emphasized that ensuring the CRC screening of their patients was a priority. It was understood that to accomplish high performance within their respective practices ongoing change was needed, and all clinicians and staff set practice-specific goals for continual improvement. To accomplish this at the practice level, regular meetings occurred with practice staff to review their efforts. The Wisconsin practice exemplified this component of the PPRNet QI model. Meeting monthly for regular office meetings and quarterly to review performance reports received from PPR-
Net, staff members became energized through these opportunities to learn the priorities of the practice. They participated in the implementation and evaluation of the activities undertaken for improvement. Clinical and office personnel implemented the tactical improvement plans developed. Patient decision making for the type of CRC screening to be used was encouraged by the clinicians and followed up on by the respective members of the team.

\section{Delivery System Design}

Evidence-based guidelines were incorporated into practice within progress note templates, which provided reminders through embedded links regarding previous CRC screening received and screening due. Wellness visits were encouraged to address regular HM needs of patients. Not surprisingly, these practices ensured patients understood that HM visits were an expectation for adults over the age of 50. The Florida concierge practice included a "free" annual physical examination to provide this wellness visit. The Colorado practice used recall systems; letters or phone calls were used to remind patients of their annual HM visit. An opportunistic approach was also used to catch patients who might 
miss HM visits through review of CRC screening status at each visit. Delegation was an important component in these practices. The Wisconsin, North Carolina, Tennessee, and Florida practices used standing orders for staff to advise patients due for screening, and provided the fecal occult blood tests (FOBT) or referrals for colonoscopy or sigmoidoscopy as indicated. Patient barriers were considered with respect for decision making about the CRC screening option. To decrease the financial impact of the screening, the Colorado practice performed sigmoidoscopy with patients whose insurance did not cover the cost of colonoscopy.

\section{Electronic Medical Record Tools}

All practices maintained accurate information in the HM tables within their EMRs. The HM table served as a standing order for staff to intervene on behalf of age- and gender-specific goals for their patients. Clinical staff members reviewed the patient's HM status at each patient contact and updated the record accordingly. The Tennessee practice used a "triple check" system and morning huddle system: HM was first reviewed with the patient by clinical staff members, who flagged the patient's EMR to remind the clinician to review the needed HM. Patient refusals for CRC screening were noted during the $\mathrm{HM}$ visit and readdressed at subsequent annual HM visits. When FOBTs were distributed or colonoscopies ordered, scheduled staff members sent themselves email reminders to be delivered on a future date that would prompt them to check on the receipt of these tests. Practices used "patient inquiries" to find patients who had orders noted on the HM table but did not have results shown. Patient-level reports (similar to patient registries) were used to identify and contact patients not up-to-date with screening and without pending orders.

\section{Patient Activation}

Repeated messages were used to activate patients due for screening and those who had not yet completed their CRC screening. For example, several staff members interacting with a patient addressed the need for screening when appropriate during or between the office visits. Office and clinical staff members discussed the choices for screening and encouraged the patient to consider the options before talking to the clinician during visits. By the time the clinician saw the patient, the HM due had already been reviewed by a nurse or medical assistant and patient educational materials had been provided.

Posters were placed in the offices to reinforce the importance of CRC screening. Office staff members interacted with patients to either schedule the colonoscopy or flexible sigmoidoscopy or used advance beneficiary notices to advise patients that they were financially responsible for FOBTs not returned. This resulted in some patients being more honest about their intentions to return them or clarified their refusal to participate in screening.

\section{Discussion}

This research identified high performers at the baseline of an intervention to improve CRC screening in adults older than age 50 at average risk in PPRNet practices, and it describes how these practices accomplished a high proportion of screening. The case study provides a set of CRC screening strategies that can be considered as primary care practices seek to improve. Previous research within PPRNet demonstrated that highperforming practices adopt variations of the PPRNet QI model. Three archetypes explained the characteristics of the highest performing practices within the A-TRIP demonstration project: technophiles, the motivated team, and the care enterprise. ${ }^{9}$ Technophiles were characterized by their skillful use of EMRs to innovate for the most efficient and effective patient care. Motivated teams referred to practices that focused on the engagement and development of their staff to optimize their contributions to improving quality of care. Care enterprises focused on specialized care management for specific conditions to provide comprehensive, guideline-concordant care. This case study provides additional evidence for these archetypes by describing ways the high-performing C-TRIP intervention practices used the features of their EMR, acted on patient information, invested in their staff as key resources to accomplish results, and offered added-value services to their patients through a focus on wellness. As practices mature in their quality improvement efforts, the dominant characteristics of the archetypes blend to accomplish many strategies for improvement.

There have been few previous studies that provide empirical evidence for how practices improve CRC screening in primary care. Literature reviews 
and opinions suggest that improving CRC screening in primary care requires addressing the barriers related to CRC screening that are faced by patients and increasing the effectiveness of communication between clinicians and patients. Developing office policies, reminder systems, and communication strategies are important to increase CRC screening. ${ }^{10}$ A community primary care practice described their adoption of 6 strategies based on the literature but had not measured or reported their performance. ${ }^{11}$ The generic concepts of a "New Model of Primary Care Delivery" were suggested-a team approach, use of information systems, involving patients in the decisions about their own screening choices, monitoring practice performance, reimbursement for nontraditional services, and training opportunities-to improve CRC screening. ${ }^{12}$ Increased CRC screening may be achieved by leveraging the contributions of practice staff. ${ }^{13}$ The PPRNet TRIP QI model embraces teamwork through the concept "involve all staff" as a foundation for "prioritizing performance." As practices learn to adopt higher levels of productivity "using EMR tools," "system redesign" follows that can result in improvements in "patient activation." This case study identified delegated responsibilities for staff to address with the patient health maintenance screening tests due. Development of staff to prioritize improvement emphasizes practice system design, and using EMR decision support tools helps to focus activities on the patients most in need of direct communication and clinician recommendation to complete CRC screening.

\section{Limitations}

The findings reported in this study are limited to primary care practices that are using EMRs and participating in practice-based research networks. Practices participating in practice-based research are typically more invested in improving quality through data sharing and benchmarking activities. Many practices using EMRs are early adopters of innovation, willing to make changes in their practice to adopt information technology to support a more efficient and effective system. These limitations are important to emphasize because only $12.4 \%$ of US physicians use comprehensive EMR systems. ${ }^{14}$ A comprehensive EMR system is integral to using the strategies discussed in this research by enabling efficient tracking and reminder systems, outreach, and follow-up to patients not reached for systematic CRC screening efforts.

Further research is needed to test these strategies in other primary care practices with EMRs. As the C-TRIP study concludes, this set of practice strategies provides a foundation for evaluation within the other practices in our study. Because primary care practices are complex adaptive systems, it is important to study the contextual factors related to primary care practice systems that underlie improvement efforts. Research to measure the implementation of C-TRIP strategies in practices outside of PPRNet is needed to further evaluate the impact of this approach to CRC screening improvement. As previous PPRNet TRIP research has demonstrated, continual refinement of a model for improvement is needed to enable primary care practices to achieve higher levels of performance within specific areas of focus.

\section{Conclusions}

Practices with a high proportion of CRC screening have a highly organized system for care to support this outcome. Primary care clinicians and their practice team members play important roles in counseling their patients to have these tests. Consistently high levels of CRC screening within PPRNet occurs when practices adapt their procedures to ensure their patients understand the importance of screening and work through the barriers to achieve successful completion of these important tests.

The authors thank Ruth Jenkins, $\mathrm{PhD}$, for data management and Loraine Roylance, MA, for coordination of the C-TRIP project.

\section{References}

1. Centers for Disease Control and Prevention. Increased use of colorectal cancer tests-United States, 2002 and 2004. MMWR Morb Mortal Wkly Rep 2006;55:308-11.

2. Brawarsky P, Brooks DR, Mucci LA, Wood PA. Effect of physician recommendation and patient adherence on rates of colorectal cancer testing. Cancer Detect Prev 2004;28:260-8.

3. Klabunde CN, Lanier D, Breslau EN, et al. Improving colorectal cancer screening in primary care: innovative strategies and future directions. J Gen Intern Med 2007;22:1195-205.

4. Feifer C, Ornstein SM. Strategies for increasing adherence to clinical guidelines and improving patient 
outcomes in small primary care practices. Jt Comm J Qual Patient Saf 2004;30:432-41.

5. Yin RK. Case study research. Design and methods, 3rd ed, vol. 5. Thousand Oaks (CA): Sage Publications; 2003.

6. Ornstein SM, Nietert PJ, Jenkins RG, et al. Improving diabetes care through a multi-component quality improvement model in a practice-based research network. Am J Med Qual 2007;22:34-41.

7. Nemeth LS, Wessell AM, Jenkins RG, Nietert PJ, Liszka HA, Ornstein SM. Strategies to accelerate translation of research into primary care within practices using electronic medical records. J Nurs Care Qual 2007;22:343-9.

8. Lincoln YS, Guba EG. Naturalistic inquiry. Beverly Hills (CA): Sage Publishers, Inc.; 1985.

9. Feifer C, Nemeth L, Nietert PJ, et al. Different paths to high-quality care: three archetypes of topperforming practice sites. Ann Fam Med 2007;5: 233-41.
10. Sarfaty M, Wender R. How to increase colorectal cancer screening rates in practice. CA Cancer J Clin 2007;57:354-66.

11. Leventhal W, Ascanio R. Recognizing and overcoming barriers to colorectal screening in primary care. J S C Med Assoc 2008;104:25-8.

12. Klabunde CN, Meissner HI, Wooten KG, Breen N, Singleton JA. Comparing colorectal cancer screening and immunization status in older Americans. Am J Prev Med 2007;33:1-8.

13. Hudson SV, Ohman-Strickland P, Cunningham R, Ferrante JM, Hahn K, Crabtree BF. The effects of teamwork and system support on colorectal cancer screening in primary care practices. Cancer Detect Prev 2007;31:417-23.

14. Hing ES, Burt CW, Woodwell DA. Electronic medical record use by office-based physicians and their practices: United States, 2006. In: Advance data from vital and health statistics. Hyattsville (MD): National Center for Health Statistics; 2007. 